\title{
EFFECT OF HEAT FLUX RATIO FROM BOTH SIDE-WALLS ON THERMAL- FLUID FLOW IN CHANNEL
}

\author{
SHUICHI TORII \\ Department of Mechanical Engineering, \\ Kagoshima University, \\ Kagoshima 890-0065, Japan \\ Tel: $+81-99-285-8245$ \\ Fax: $+81-99-285-8246$ \\ E-mail: torii@mech.kagoshima-u.ac.jp
}

\author{
WEN-JEI YANG \\ Mechanical Engineering and Applied \\ Mechanics, The University of Michigan, \\ Ann Arbor, Michigan 48109, U.S.A.
}

Tel: 734-764-9910

Fax: 734-747-3170

E-mail: wjyang@engin.umich.edu

\begin{abstract}
Numerical analysis is performed to investigate transport phenomena in channel flows under uniform heating from both side-walls. Emphasis is placed on an effect of heat flux ratio from both sides on the velocity and thermal fields. The twoequation heat-transfer model is employed to determine thermal eddy diffusivity. It is found that (i) under strong heating from both walls, laminarization, i.e., a substantial deterioration in heat transfer performance occurs as in the circular tube flow case, (ii) during the laminarization process, both the velocity and temperature gradients in the vicinity of the heated walls decrease along the flow, resulting in a substantial attenuation in both the turbulent kinetic energy and the temperature variance over the entire channel cross section and (iii) in contrast, laminarization is suppressed in the presence of oneside-heating, because turbulent kinetic energy is produced in the vicinity of the other insulated wall. Therefore, an occurrence of laminarization in the channel is affected by the ratio of heat flux from both side-walls.
\end{abstract}

\section{NOMENCLATURE}

$\begin{array}{ll}c_{p} & \text { specific heat at constant pressure, } \mathrm{J} /(\mathrm{kgK}) \\ \mathrm{C}_{\mu}, \mathrm{C}_{1}, \mathrm{C}_{2} & \begin{array}{l}\text { empirical constants of } \mathrm{k}-\varepsilon \text { model } \\ \mathrm{C}_{\lambda}, \mathrm{CP}_{\mathrm{P}}, \mathrm{C}_{\mathrm{P} 2}\end{array} \\ & \begin{array}{l}\text { turbulence model constants for temperature } \\ \text { field }\end{array}\end{array}$

Copyright (C) 2002 The American Institute of Aeronautics and Astronautics, Inc. All rights reserved.

\begin{tabular}{|c|c|}
\hline $\mathrm{CD}_{1}, \mathrm{CD}_{2}$ & $\begin{array}{l}\text { turbulence model constants for temperature } \\
\text { field }\end{array}$ \\
\hline $\mathrm{h}$ & heat transfer coefficient, $\mathrm{W} / \mathrm{m}^{2} \mathrm{~K}$ \\
\hline $\mathrm{H}$ & channel height, $\mathrm{m}$ \\
\hline $\mathrm{f}$ & friction coefficient \\
\hline$f \mu, f_{1}, f_{2}$ & model functions of $\mathrm{k}-\varepsilon$ model \\
\hline $\mathrm{f}_{\lambda}, \mathrm{fP}_{\mathrm{P} 1}, \mathrm{fP} 2$ & turbulence model functions of temperature \\
\hline & field \\
\hline$f_{D} 1, f_{D} 2$ & turbulence model functions of temperature \\
\hline & field \\
\hline $\mathrm{g}$ & acceleration of gravity, $\mathrm{m} / \mathrm{s}^{2}$ \\
\hline G & mass flux of gas flow, $\mathrm{kg} /\left(\mathrm{m}^{2} \mathrm{~s}\right)$ \\
\hline Gr & Grashof number, $\mathrm{gq}_{\mathrm{w}} \mathrm{H}^{4} /\left(v^{2} \lambda \mathrm{T}\right)_{\text {in }}$ \\
\hline $\mathrm{H}$ & channel height, $\mathrm{m}$ \\
\hline $\mathrm{k}$ & turbulent kinetic energy, $\mathrm{m}^{2} / \mathrm{s}^{2}$ \\
\hline ML & the number of mesh \\
\hline $\mathrm{N}$ & heat flux ratio, $\mathrm{q}_{\mathrm{w} 2} / \mathrm{q}_{\mathrm{w} 1}$ \\
\hline $\mathrm{Nu}$ & Nusselt number, $2 \mathrm{Hh} / \lambda$ \\
\hline$P$ & time-averaged pressure, $\mathrm{Pa}$ \\
\hline $\operatorname{Pr}$ & Prandtl number \\
\hline $\operatorname{Pr}_{\mathrm{t}}$ & turbulent Prandtl number \\
\hline $\mathrm{q}_{\mathrm{w} 1}, \mathrm{q}_{\mathrm{w} 2}$ & $\begin{array}{l}\text { heat fluxes at } \mathrm{y}=0 \text { and } \mathrm{H} \text {, respectively, } \\
\mathrm{W} / \mathrm{m}^{2}\end{array}$ \\
\hline $\mathrm{q}^{+} \mathrm{w}$ & dimensionless heat flux parameter, Eq. (14) \\
\hline
\end{tabular}


$-\overline{u_{i} t}$

$\mathrm{x}$

$\mathrm{xi}$

$\mathrm{y}$

$\mathrm{y}^{+}$

\section{Greek Letters}

$\alpha$

$\rho$

$\delta$

$\varepsilon$

$\varepsilon_{\mathrm{t}}$

$\lambda, \lambda_{\mathrm{t}}$

$\mu, \mu_{\mathrm{t}}$

$v$

$\sigma_{\mathrm{k}}, \sigma_{\varepsilon}, \sigma_{\mathrm{h}}, \sigma_{\phi}$

$\theta$

$\theta^{+}$
Reynolds number, $2 \mathrm{u}_{\mathrm{m}} \mathrm{H} / \mathrm{v}$

turbulent Reynolds number, $\mathrm{k}^{2} /(\varepsilon v)$

dimensionless distance, $\mathrm{y}^{+}$

Stanton number, $\mathrm{q}_{\mathrm{w}} /\left(\rho \mathrm{c}_{\mathrm{p}} \mathrm{u}_{\mathrm{m}}\left(\mathrm{T}_{\mathrm{W}}-\mathrm{T}_{\mathrm{b}}\right)\right)$

time-averaged temperature, $\mathrm{K}$

fluctuating temperature component, $\mathrm{K}$

friction temperature, $\mathrm{q}_{\mathrm{w}} /\left(\rho \mathrm{p}_{\mathrm{p}} \mathrm{u}^{*}\right), \mathrm{K}$

temperature variance, $\mathrm{K}^{2}$

time-averaged velocity components in axial, and normal-wall direction, respectively, $\mathrm{m} / \mathrm{s}$ time-averaged and fluctuating velocity components in the $x_{i}$ directions, $\mathrm{m} / \mathrm{s}$ mean velocity over channel cross section, $\mathrm{m} / \mathrm{s}$ fluctuating velocity components in axial, wall-normal and tangential directions, respectively, $\mathrm{m} / \mathrm{s}$

friction velocity, $\mathrm{m} / \mathrm{s}$

dimensionless velocity, $\mathrm{U} / \mathrm{u}^{*}$

Reynolds stress, $\mathrm{m}^{2} / \mathrm{s}^{2}$

turbulent heat flux, $\mathrm{mK} / \mathrm{s}$

axial coordinate, $\mathrm{m}$

coordinates, $\mathrm{m}$

wall-normal coordinate, $\mathrm{m}$

dimensionless distance, $u^{*} \delta / v$

thermal diffusivity, $\mathrm{m}^{2} / \mathrm{s}$

density, $\mathrm{kg} / \mathrm{m}^{3}$

distance from wall, $\mathrm{m}$

turbulent energy dissipation rate, $\mathrm{m}^{2} / \mathrm{s}^{3}$

dissipation rate of $\mathrm{t}^{2}, \mathrm{~K} / \mathrm{s}^{2}$

molecular and turbulent thermal

conductivities, respectively, $\mathrm{W} /(\mathrm{Km})$

molecular and turbulent viscosities,

respectively, Pa sec

fluid kinematic viscosity, $\mathrm{m}^{2} / \mathrm{s}$

turbulence model constants for diffusion of $\mathrm{k}$,

$\varepsilon, \overline{t^{2}}$ and $\varepsilon_{t}$, respectively

tangential direction

dimensionless temperature, $\theta^{+}=\frac{T-T_{c}}{T_{w}-T_{c}}$

\section{Subscripts}

inlet

$\max$

$\mathrm{W}$

Superscripts

\section{INTRODUCTION}

When a gas in a circular pipe is heated with extremely high heat flux, the flow may be laminarized; that is, a transition from turbulent to laminar flows occurs at a higher Reynolds number than the usual critical value, i.e., $\mathrm{Re}=2,300$. This phenomenon is referred to as laminarization. Both the criteria for its occurrence and its heat transfer characteristics have been reported by several investigators [1-6]. In order to investigate an effect of passage geometry on an occurrence of the laminarizing gas flow, Torii et al. [7] and Fujii et al. [8] deal with the thermal-fluid transport phenomena in concentric annuli under high heat flux heating. They disclosed that (i) when the gas flow is strongly heated with the same heat flux level from inner and outer tube walls, the local heat transfer coefficients on both walls approach the laminar values along the flow; that is, the laminarization takes place; (ii) the existing criteria of laminarization for circular tube flows can be applied to annular flows as well if the occurrence of laminarization is estimated using a dimensionless heat flux parameter $\mathrm{q}^{+}{ }_{\mathrm{W}}$; but (iii) annular flows heated strongly from only one side are less vulnerable to laminarization even if the usual criteria are satisfied.

The purpose of the present study is to investigate thermalfluid flow transport phenomena in a channel in which both walls are individually heated with different heat fluxes. The $\mathrm{t}^{2}-\varepsilon \mathrm{t}$ heat transfer model proposed by Torii and Yang [9] and the $\mathrm{k}-\varepsilon$ turbulence model of Torii et al. [10] are employed to reveal the mechanism of heat transport phenomena. The turbulent thermal conductivity $\lambda_{\mathrm{t}}$ is determined using the temperature variance $\mathrm{t}^{2}$ and the dissipation rate of temperature fluctuations $\varepsilon \mathrm{t}$, together with $\mathrm{k}$ and $\varepsilon$. Emphasis is placed on the effect of heat flux ratio from both sides on the velocity and thermal fields, based on the numerical results, i.e., the turbulent kinetic energy, temperature variance, velocity, and temperature profiles. 


\section{GOVERNING EQUATIONS AND NUMERICAL PROCEDURES}

Consideration is given to a steady turbulent flow in a strongly heated channel. The physical configuration and the coordinate system are shown in Fig. 1. In this analysis, the dependence of gas properties on temperature, as well as changes in gas density, must be taken into account [11]. The continuity, momentum and energy for an incompressible fluid are represented in the tensor form as:

Continuity equation:

$$
\frac{\partial \rho U_{i}}{\partial x_{i}}=0
$$

Momentum equations:

$\rho U_{j} \frac{\partial U_{i}}{\partial x_{j}}=-\frac{\partial P}{\partial x_{i}}+\frac{\partial}{\partial x_{j}}\left[\mu\left(\frac{\partial U_{i}}{\partial x_{j}}+\frac{\partial U_{j}}{\partial x_{i}}\right)-\rho \overline{u_{i} u_{j}}\right]$

Energy equation:

$c_{p} \rho U_{i} \frac{\partial T}{\partial x_{i}}=\frac{\partial}{\partial x_{i}}\left(\lambda \frac{\partial T}{\partial x_{i}}-c_{p} \rho \overline{u_{i} t}\right)$.

These equations follow from the derivation process proposed by Schlichting [11]. Here, the turbulent fluctuations of $\lambda, \mu$ and $c_{p}$ through temperature fluctuation have been discounted. The term for body force in the momentum equation is also negligible, because a small diameter tube was employed and throughout the calculation, the buoyancy parameter $\mathrm{Gr} / \mathrm{Re}_{\mathrm{in}}{ }^{2}$ was less than 0.1 so that forced convection may be expected to dominate.

The Reynolds stress $-\bar{\rho} \overline{\mathrm{u}_{\mathrm{i}} \mathrm{u}_{\mathrm{j}}}$ in Eq. (2) is obtained using the Boussinesq approximation as:

$-\rho \overline{u_{i} u_{j}}=-\frac{2}{3} \delta_{i j} \rho k-\mu_{t}\left(\frac{\partial U_{i}}{\partial x_{j}}+\frac{\partial U_{j}}{\partial x_{i}}\right)$

Here, the turbulent viscosity $\mu_{\mathrm{t}}$ is expressed in terms of the turbulent kinetic energy $\mathrm{k}$ and its dissipation rate $\varepsilon$ through the Kolmogorov-Prandtl's relation [12] as

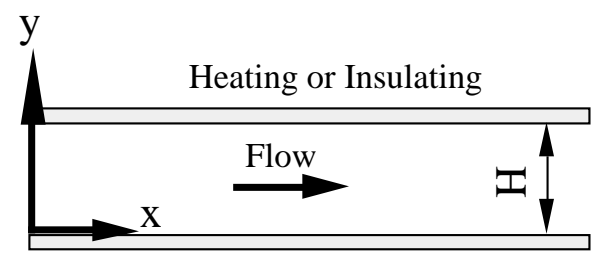

Heating

Figure 1 A schematic of the physical system and coordinates
$\mu_{t}=C_{\mu} f_{\mu} \rho \frac{k^{2}}{\varepsilon}$

$\mathrm{C}_{\mu}$ and $\mathrm{f}_{\mu}$ are a model constant and a model function, respectively. Torii et al. [10] developed a low Reynolds number version of the $\mathrm{k}-\varepsilon$ turbulence model capable of reproducing the transition from turbulent to laminar flows originally developed by Nagano and Hishida [13]. The same model [10] is employed here. Both transport equations read

$$
\begin{aligned}
& \rho U_{j} \frac{\partial k}{\partial x_{j}}=\frac{\partial}{\partial x_{j}}\left[\left(\mu+\frac{\mu_{t}}{\sigma_{k}}\right) \frac{\partial k}{\partial x_{j}}\right]-\rho \overline{u_{i} u_{j}} \frac{\partial U_{i}}{\partial x_{j}}-\rho \varepsilon-2 \mu\left(\frac{\partial \sqrt{k}}{\partial x_{j}}\right)^{2} \\
& \rho U_{j} \frac{\partial \varepsilon}{\partial x_{j}}=\frac{\partial}{\partial x_{j}}\left[\left(\mu+\frac{\mu_{t}}{\sigma_{\varepsilon}}\right) \frac{\partial \varepsilon}{\partial x_{j}}\right]-C_{1} f_{1} \rho \frac{\varepsilon}{k} \overline{u_{i} u_{j}} \frac{\partial U_{i}}{\partial x_{j}} \\
& -C_{2} f_{2} \rho \frac{\varepsilon^{2}}{k}+v \mu_{t}\left(1-f_{\mu}\right)\left(\frac{\partial^{2} U_{i}}{\partial x_{j}^{2}}\right)^{2}
\end{aligned}
$$

The empirical constants and model functions in Eqs. (5), (6) and (7) are summarized in reference [10]. In the present study, the k- $\varepsilon$ model for the velocity field is applied to analyze the strongly heated gas flows in a channel because it can predict laminarization in a stationary pipe with high flux heating [10].

The turbulent heat flux $-c_{p} \rho \overline{u_{i} t}$ in Eq. (3) can be expressed in the following form:

$$
\begin{aligned}
& -c_{p} \rho \overline{u_{i} t}=\lambda_{t} \frac{\partial T}{\partial x_{i}} \\
& =C_{\lambda} f_{\lambda} c_{p} \rho k \sqrt{\frac{k}{\varepsilon} \frac{\overline{t^{2}}}{\varepsilon_{t}}} \frac{\partial T}{\partial x_{i}}
\end{aligned}
$$

where $\mathrm{C}_{\lambda}$ is a model constant and $\mathrm{f}_{\lambda}$ is a model function. In order to obtain $\bar{t}^{2}$ and $\varepsilon_{t}$ in Eq. (9), Torii and Yang [9] proposed the modified two-equation heat-transfer model capable of expressing the heat-transfer characteristics in the laminar and transition regions, whose model is originally developed by Nagano and Kim [14]. The transport equations for $\mathrm{t}^{2}$ and $\varepsilon_{\mathrm{t}}$ are expressed as 
$\rho U_{j} \frac{\partial \overline{t^{2}}}{\partial x_{j}}=\frac{\partial}{\partial x_{j}}\left[\left(\frac{\lambda}{c_{p}}+\frac{\lambda_{t}}{\sigma_{h} c_{p}}\right) \frac{\partial \overline{t^{2}}}{\partial x_{j}}\right]-2 \rho \overline{u_{j} t} \frac{\partial T}{\partial x_{j}}-2 \rho \varepsilon_{t}-2 \frac{\lambda}{c_{p}}\left(\frac{\partial \sqrt{\overline{t^{2}}}}{\partial x_{j}}\right)^{2}$

and

$\rho U_{j} \frac{\partial \varepsilon_{t}}{\partial x_{j}}=\frac{\partial}{\partial x_{j}}\left[\left(\frac{\lambda}{c_{p}}+\frac{\lambda_{t}}{\sigma_{\phi} c_{p}}\right) \frac{\partial \varepsilon_{t}}{\partial x_{j}}\right]+C_{p 1} f_{p 1} \frac{\varepsilon \lambda_{t}}{k c_{p}}\left(\frac{\partial T}{\partial x_{j}}\right)^{2}$

$+C_{p 2} f_{p 2} \frac{\varepsilon_{t} \mu_{t}}{k}\left(\frac{\partial U}{\partial x_{j}}\right)^{2}-C_{D 1} f_{D 1} \rho \frac{\varepsilon_{t}^{2}}{\bar{t}^{2}}-C_{D 2} f_{D 2} \rho \frac{\varepsilon \varepsilon_{t}}{k}+\frac{\alpha \lambda_{t}}{c_{p}}\left(1-f_{t}\right)\left(\frac{\partial^{2} T}{\partial x_{j}}\right)^{2}$

respectively. The empirical constants and model functions in Eqs. (8), (9) and (10) are listed in reference [9].

A set of governing equations is solved using the control volume finite-difference procedure developed by Patankar [15]. The power-law scheme for the convection-diffusion formulation is employed to link the convection-diffusion terms. Since all turbulent quantities as well as the timeaveraged streamwise velocity vary rapidly in the near-wall region, the size of nonuniform cross-stream grids increases with a geometric ratio from the wall towards the center line. The maximum control volume size near the center line is always kept at less than $1 \%$ of channel height. To ensure the accuracy of calculated results, at least two control volumes are located in the viscous sublayer. Throughout the numerical calculations, the number of control volumes is properly selected between 72 and 98 to obtain a grid-independent solution, resulting in no appreciable difference between the numerical results with different grid spacing, as mentioned below. The discretized equations are solved from the inlet in the downstream direction by means of a marching procedure, since these equations are parabolic. The maximum step-size in the streamwise direction is limited to five times the minimum size in the wall-normal direction of the control volume. At each axial location, the thermal properties for control volumes are determined from the axial pressure and temperature using a numerical code of reference [16].

The hydrodynamically fully-developed isothermal flow is assumed at the starting point of the heating section. The following boundary conditions are used at the walls:

$\mathrm{y}=0: \quad \mathrm{U}=\mathrm{k}=\varepsilon=\mathrm{t}^{2}=\varepsilon_{\mathrm{t}}=0$,

$$
-\frac{\partial T}{\partial y}=\frac{q_{w 1}}{\lambda_{w}} \text { (constant heat flux) }
$$

$\mathrm{y}=\mathrm{H}: \quad \mathrm{U}=\mathrm{k}=\varepsilon=\overline{\mathrm{t}^{2}}=\varepsilon_{\mathrm{t}}=0$,

$\frac{\partial T}{\partial y}=\frac{q_{w 2}}{\lambda_{w}}$ (constant heat flux)
Based on the above boundary conditions, the computations are processed in the following order:

1. The initial values of $\mathrm{U}, \mathrm{k}, \varepsilon, \overline{\mathrm{t}^{2}}$ and $\varepsilon_{\mathrm{t}}$ are specified andassigned a constant axial pressure gradient. Here, the values of $U, k$ and $\dot{\varepsilon}$ the hydrodynamically fully-developed isothermal channel flow are employed as the initial values.

2. The equations of $\mathrm{U}, \mathrm{k}, \varepsilon, \mathrm{T}, \overline{\mathrm{t}^{2}}$ and $\varepsilon_{\mathrm{t}}$ are solved using the boundary conditions given here.

3. Step 2 is repeated until the criterion of convergence is satisfied. It is set at

$\max \left|\frac{\phi^{M}-\phi^{M-1}}{\phi_{\max }^{M-1}}\right| \leq 10^{-4}$

for all variables $\phi \mathrm{U}, \mathrm{k}, \varepsilon, \mathrm{T}, \overline{\mathrm{t}^{2}}$ and $\left.\varepsilon_{\mathrm{t}}\right)$. The superscripts $M$ and $M-1$ in Eq. (11) indicate two successive iterations, while the subscript "max" refers to a maximum value over the entire field of iterations.

4. New values of $\mathrm{U}, \mathrm{k}, \varepsilon, \mathrm{T}, \overline{\mathrm{t}^{2}}$ and $\varepsilon_{\mathrm{t}}$ are calculated by correcting the axial pressure gradient.

5. Steps 2-4 are repeated until the conservation of the streamwise flow rate is satisfied under the criterion

$\left|\frac{\int U_{c p} d y-\int U_{i n} d y}{\int U_{i n} d y}\right| \leq 10^{-5}$

and the convergent values of $\mathrm{U}, \mathrm{k}, \varepsilon, \mathrm{T}, \overline{\mathrm{t}^{2}}$ and $\varepsilon_{\mathrm{t}}$ are evaluated. Here, $U_{c p}$ is the axial velocity under the correction process and $\mathrm{U}_{\mathrm{in}}$ is that at the inlet of the channel.

6. Steps 2-5 are repeated until $\mathrm{x}$ reaches the desired length from the inlet.

In the present study, the nondimensional heat flux parameter $\mathrm{q}^{+} \mathrm{w}$ is employed to indicate the magnitude of heat flux at the channel wall. This parameter, originally proposed by Nemira et al. [17] for determining thermal transport phenomena in concentric annular gas flows, is defined as

$$
q_{w}^{+}=\frac{d_{\text {in }} q_{\text {in }}+d_{\text {out }} q_{\text {out }}}{d_{\text {in }}+d_{\text {out }}} \frac{1}{\left(G c_{p} T\right)_{\text {inlet }}}
$$

where $d_{i n}$ and $d_{\text {out }}$ are, respectively, the inner and outer tube diameters of the annulus, and qin and qout correspond to heat fluxes on the inner and outer walls of the annulus. When applying Eq. (13) to two-dimensional channel, it is reduced as 


$$
\begin{aligned}
& q_{w}^{+}=\frac{q_{w 1}+q_{w 2}}{2} \frac{1}{\left(G_{c_{p}} T\right)_{\text {inlet }}} \\
& =\frac{q_{w 1}(1+N)}{2} \frac{1}{\left(G_{c_{p}} T\right)_{\text {inlet }}}
\end{aligned}
$$

The ranges of the parameters are the nondimensional heat flux parameter $\mathrm{q}^{+}{ }_{\mathrm{w}}<0.009$; the inlet Reynolds number, i.e., the Reynolds number at the onset of heating $\operatorname{Re}_{\mathrm{in}}=8,500$; heat flux ratio of both side walls $\mathrm{N}=0-1$ and the inlet gas (nitrogen) temperature $\mathrm{T}_{\mathrm{in}}=273 \mathrm{~K}$.

Simulations with grids of various degrees of coarseness are conducted to determine the required resolution for gridindependent solutions. Throughout the numerical calculations, the number of control volumes, ML, is properly selected between 72 and 98 over the cross-section of the concentric annulus. Consequently, there was only a slightly appreciable differences, $0.5 \%$, between numerical results with different radial grid spacing.

\section{RESULTS AND DISCUSSION}

Figure 2 illustrates the local heat-transfer coefficients in strongly heated channel flows in the form of Stanton number St versus Reynolds number $\mathrm{Re}$, with $\mathrm{q}^{+}{ }_{\mathrm{W}}$ as the parameter. Figures 2(a) and (b) correspond to the results for both-sided and one-sided heating, i.e., $\mathrm{N}=1$ and 0 , respectively. Theoretical solutions for turbulent and laminar heat transfer in the thermally and hydrodynamically fully-developed channel flows [18] are superimposed in the figure in a solid straight lines. In Fig. 2, a reduction in the Reynolds number signifies a change in the location along the channel, because the Reynolds number decreases from the inlet with the axial distance resulting from an increase in the molecular viscosity by heating. The numerical results for both cases show that the local Stanton numbers at $\mathrm{q}^{+}{ }_{\mathrm{w}}=0.0025$ first decrease in the thermal entrance region, then increase, approaching the turbulent correlation further downstream. This suggests that no laminarization will occur. On the contrary, as the flow goes downstream, the predicted Stanton numbers at $\mathrm{q}^{+} \mathrm{w}$ $=0.0043$ depart from the turbulent heat-transfer correlation and approach the laminar correlation, as shown in Fig. 2(a). Bankston [1] pointed out that the substantial reduction in St along the flow is due to the occurrence of laminarization. In other words, if the channel is strongly heated from both walls, the fluid flow is laminarized as in the circular tube flow case.

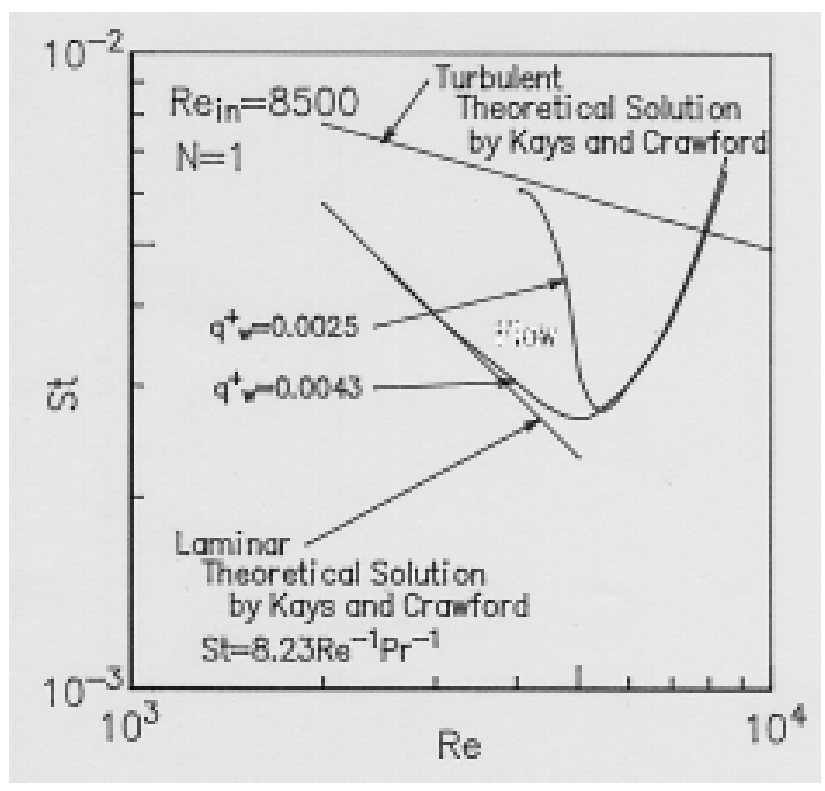

(a) both-sided heating

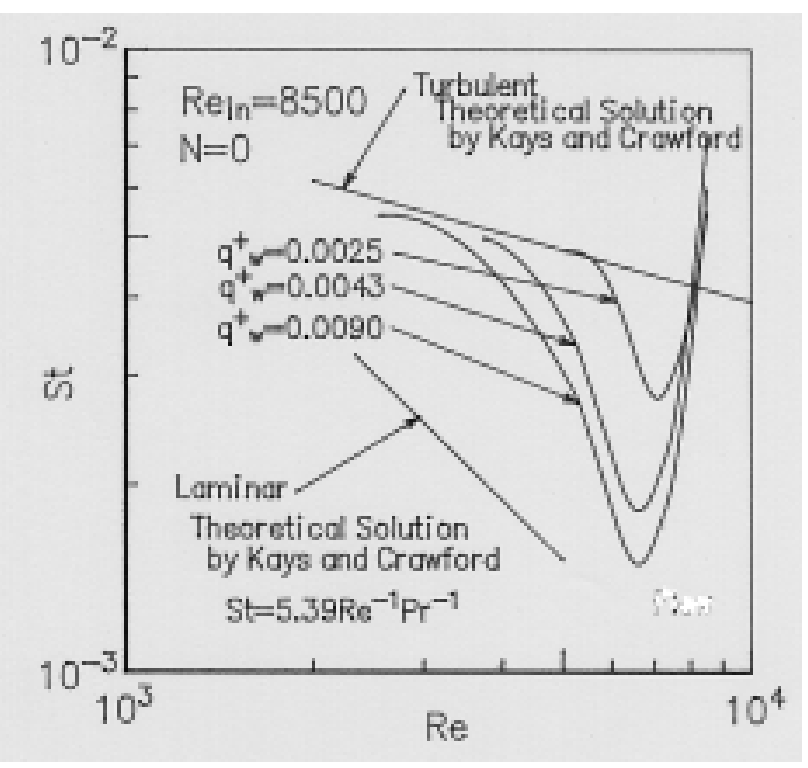

(b) one-sided heating

Figure 2 Predicted local Stanton number with Reynolds number as a function of nondimensional heat flux parameters.

However, in Fig. 2(b) the local Stanton number at $\mathrm{q}^{+}{ }_{\mathrm{w}}=0.0043$ decreases in the thermal entrance region, then recovers along the flow and eventually approaches the turbulent correlation equation further downstream. This transport phenomenon provides a striking contrast to the bothsided heating case at the corresponding dimensionless heat

American Institute of Aeronautics and Astronautics 
flux. When heat flux on a single heating wall becomes higher, the predicted local Stanton number, as seen in Fig. 2(b), approaches the turbulent correlation downstream, even at $\mathrm{q}^{+}{ }_{\mathrm{w}}=0.0090$, i.e., a level that under two-sided heating completely laminarizes the tube flow. In other words, if a channel is heated exclusively from only one wall, the fluid flow can not be laminarized and is a striking contrast to the tube flow case. This behavior in the channel flow is the same as the thermal-fluid transport characteristics in the annuli heated strongly from only one side, as mentioned in introduction. The occurrence of laminarization is thus clearly affected by $\mathrm{q}^{+} \mathrm{w}$ and $\mathrm{N}$.

An attempt is made to explore the heat and fluid flow mechanisms for two-sided and both-sided heating, based on the numerical results at $\mathrm{q}^{+}{ }_{\mathrm{w}}=0.0043$, i.e., turbulent kinetic energy, temperature variance, velocity and temperature profiles. Figure 3 illustrates the wall-normal distributions of the time-averaged streamwise velocity $\mathrm{U} / \mathrm{U}_{\max }$ at three different axial locations: $\mathrm{x} / \mathrm{H}=0,60$, and 120 . Figures 3(a) and (b) show the numerical results for $\mathrm{N}=1$ and 0 , respectively. The velocity $U$ is normalized by the maximum value $\mathrm{U}_{\max }$ at each axial location. The laminar flow profile is superimposed in the figure as a solid line, for comparison. In Fig. 3(a) a substantial reduction of the velocity gradient takes place in the flow direction and the velocity profile approaches laminar one in the downstream region. In contrast, Fig. 3(b) shows that the velocity gradients at the walls are slightly diminished along the flow, particularly in the vicinity of the heating wall, and the velocity profile is substantially different from the laminar one in the flow direction. The corresponding streamwise variations of the turbulent kinetic energy $\mathrm{k}$ for $\mathrm{N}=1$ and 0 are illustrated in Figs. 4(a) and (b), respectively. Here, the numerical results are normalized by a square of the wall friction velocity at the onset of heating $\mathrm{u}^{* 2}$. It is observed in Fig. 4(a) that the turbulent kinetic energy level for both-sided heating, i.e., $\mathrm{N}=1$ is extremely attenuated over the whole channel cross section in the flow direction due to high flux heating. This streamwise behavior is in accordance with that of the velocity distribution in Fig. 3(a). The substantial attenuation in both velocity and turbulent kinetic energy is the same as the flow characteristics in the laminarizing flow in both the heated tube $[9,10]$ and the annuli heated from both inner and outer tube walls [7].

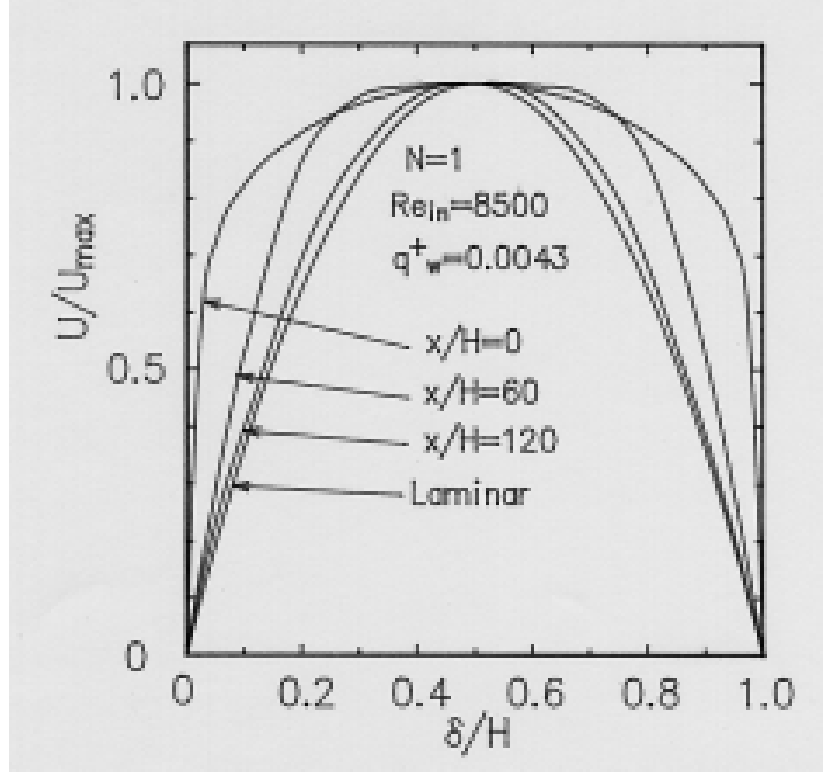

(a)

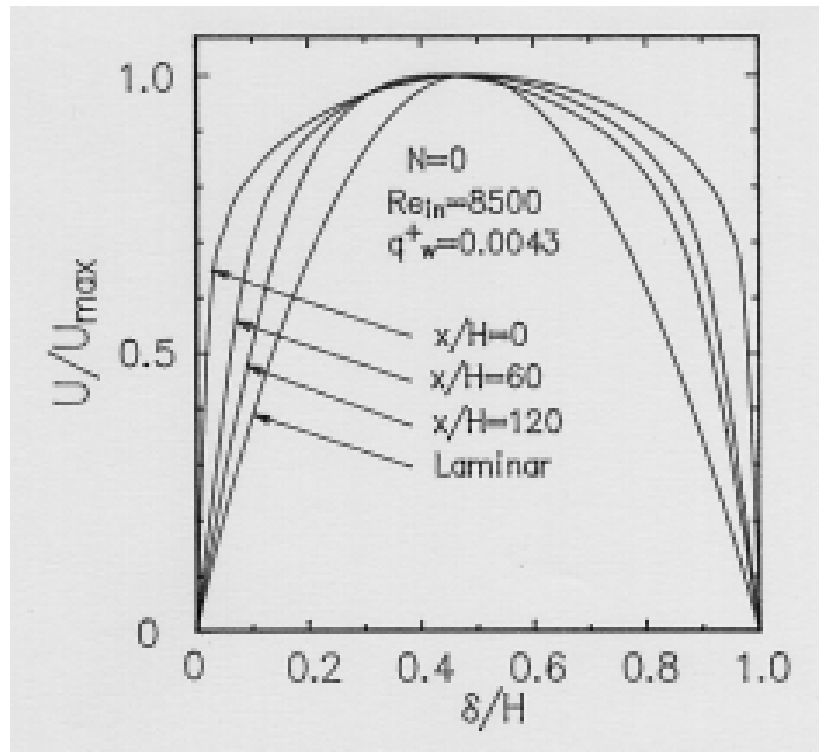

(b)

Figure 3 Streamwise variation of time-averaged velocity profiles in a strongly heated flow with different axial locations, (a) both-sided heating and (b) one-sided heating.

However, numerical results for $\mathrm{N}=0$ show that as the flow progresses, appreciable turbulent kinetic energy still remains in the velocity field, particularly near the insulated wall, as seen in Fig. 4(b). This behavior corresponds to that of the velocity distribution in Fig. 3(b) and is similar to that in the annular flow heated from one-seided wall. That is, when the 6 
channel flow is strongly heated from one wall, the turbulent kinetic energy is severely diminished in the vicinity of the heating wall, while it is intensified near the opposite wall along the flow. All these results consistently show that (i) if the flow is strongly heated from both side walls of the channel, laminarization occurs, and (ii) the trend towards laminarization from the strongly heated wall is always suppressed by the turbulent kinetic energy produced in the region near the insulated wall, where heat flux is added to the flow from one wall only.

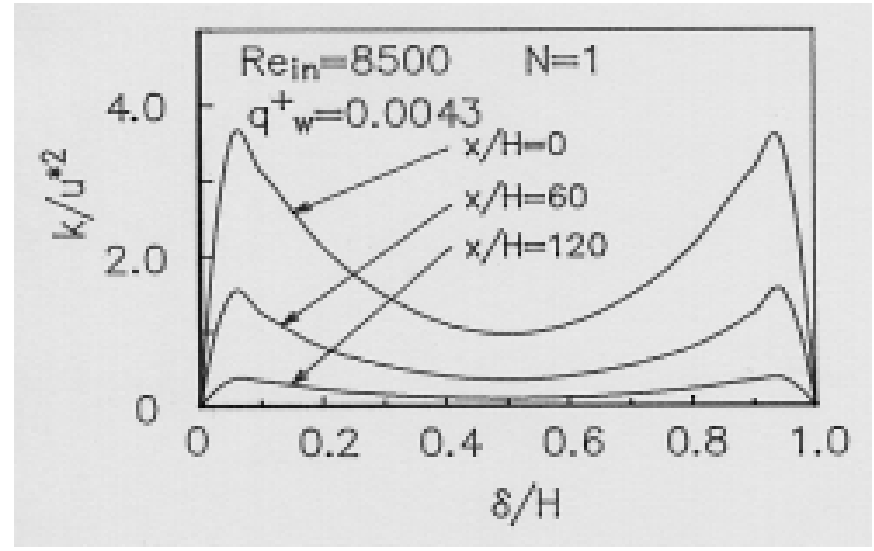

(a)

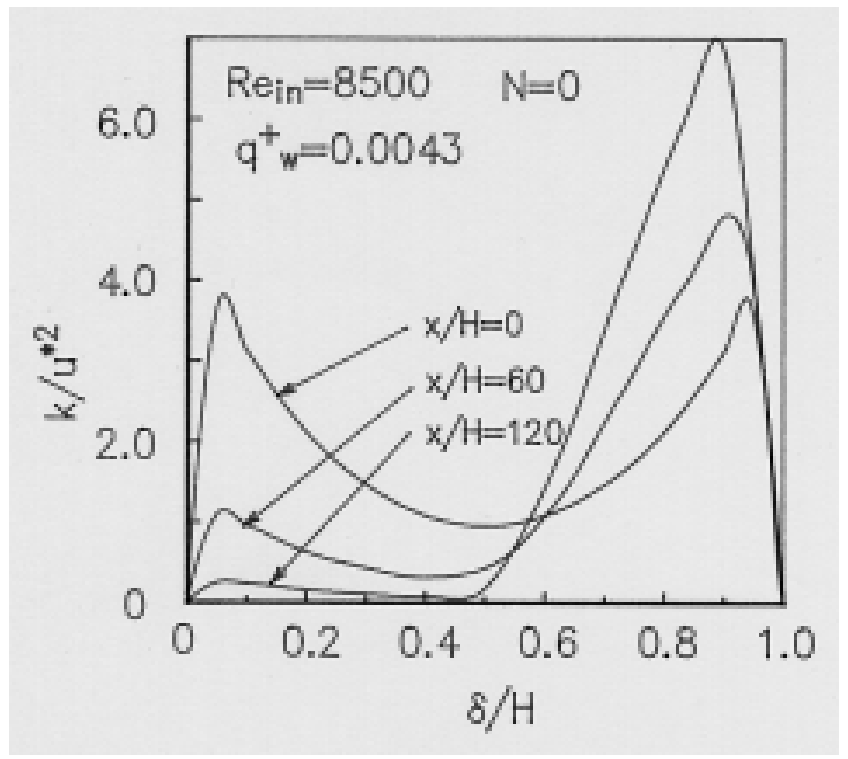

(b)

Figure 4 Streamwise variation of turbulent kinetic energy profiles in a strongly heated flow with different axial locations, (a) both-sided heating and (b) one-sided heating.

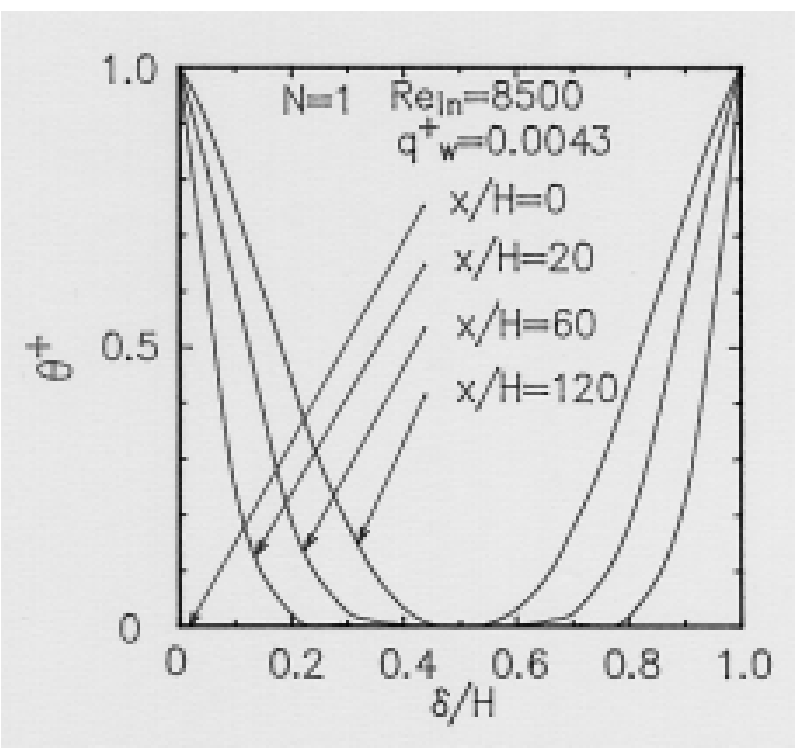

(a)

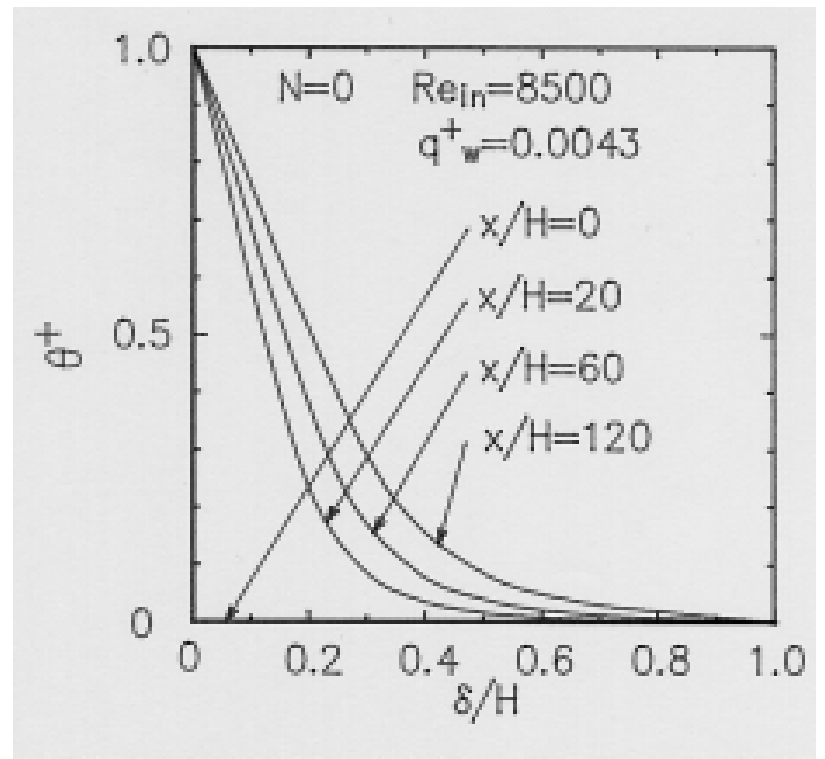

(b)

Figure 5 Streamwise variation of time-averaged temperature profiles in a strongly heated flow with different axial locations, (a) both-sided heating and (b) one-sided heating.

Figures 5(a) and (b) show streamwise variations in the time-averaged temperature profile $\theta^{+}$for $\mathrm{N}=1$ and 0 , respectively. Numerical results are obtained at different axial locations: $x / H=20,60$, and 120 . The substantial reduction in the temperature gradient for $\mathrm{N}=1$ occurs at the wall along the flow (Fig. 5(a)), while numerical results for $\mathrm{N}=0$ reveal only a 
slight reduction in the temperature gradient at the heated wall in the flow direction (Fig. 5(b)). The corresponding radial distributions of the temperature variance $\mathrm{t}^{2}$ for $\mathrm{N}=1$ and 0 , are illustrated in Figs. 6(a) and (b), respectively. Here, the temperature variance is divided by the square of the friction temperature $\mathrm{t}^{*}$ at each axial location. As the flow moves, there is a substantial reduction in $\mathrm{t}^{2}$ for $\mathrm{N}=1$ over the whole cross-section of the channel, as seen in Fig. 6(a). This behavior implies attenuation in the temperature fluctuations in the thermal field. For $\mathrm{N}=0$, as the flow moves along the channel, the temperature variance level $\mathrm{t}^{2}$ is somewhat diminished in the vicinity of the heated channel wall because of a decrease in the temperature gradient near that wall, while $\mathrm{t}^{2}$ is intensified at the other wall. In other words, appreciable temperature fluctuations remain in the thermal field when the flow is heated from one wall only.

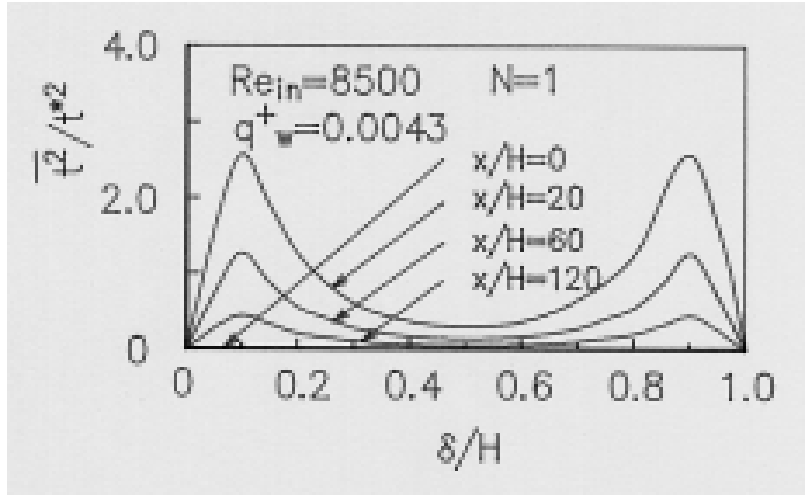

(a)

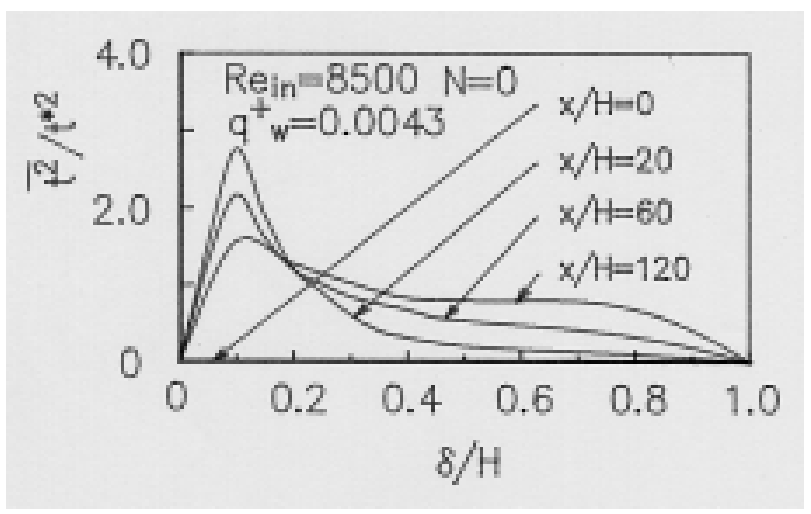

(b)

Figure 6 Streamwise variation of temperature variance profiles in a strongly heated flow with different axial locations, (a) both-sided heating and (b) one-sided heating.
Since the eddy diffusivity concept is employed to determine the turbulent heat flux $-c_{p} \bar{\rho} \overline{v t}$ in Eq. (3), $\lambda_{t}$ is directly related to $\mathrm{k}, \varepsilon, \mathrm{t}^{2}$ and $\varepsilon_{\mathrm{t}}$ as depicted in Eq. (8). Hence, substantial reductions in the turbulent kinetic energy and temperature variance result in attenuation in the Stanton number, as shown in Fig. 2(a). One may thus conclude that a flow in a channel heated with uniform wall heat flux from both walls is laminarized as in the tube and concentric annular flows. In contrast, a streamwise deterioration of the Stanton number in Fig. 2(b) is suppressed by the presence of the turbulent kinetic energy produced in the vicinity of the insulated wall, even if the heat flux parameter satisfies the laminarization criterion for circular tube flows. That is, the trend towards laminarizing the flow is always suppressed if the heat flux is added to the flow from only one wall, even at levels that cause laminarization in a circular tube flow.

Next is to study the effect of $\mathrm{N}$ on an occurrence of the laminarization of the flow in the two-dimensional channel. First of all, conditions should be specified under which the flow is certainly laminarized. Torii et al. [10] established the criterion for the laminarizing flow in a tube with high heat flux using the $k$ - $\varepsilon$ turbulence model. That is, laminarization occurs when the calculated turbulent kinetic energy at the location 150 diameters downstream from the inlet becomes lower than one-tenth of the inlet value. The same idea, in which the criterion is for the turbulent kinetic energy at $\mathrm{x} / \mathrm{H}=150$ to be lower than one-tenth of its inlet value, is adopted in the present study. This is because the streamwise variation of a turbulent kinetic energy in the laminarizing flow, as depicted in Fig. 4(a), is similar to that in the strongly heated tube case [10]. The predicted criterion for the laminarization of a two-dimensional channel flow is depicted in Fig. 7, in the form of $\mathrm{q}^{+}{ }_{\mathrm{w}}$ versus N. Here, the existing criteria for the circular tube and the predicted criteria for the circular and annular tube flows [7, 10] are superimposed in the figure for comparison. It is observed that the Predicted criterion at $\mathrm{N}=1$ is similar to the circular and annular tube cases. One may thus conclude that a flow in a twodimensional channel heated with uniform wall heat flux from both sided walls is laminarized at the same heating level as the circular and annular tube flow cases, while the criterion is increased with an decrease in N. In other words, if a channel is heated at the different heat fluxes from both walls, the fluid flow can not be laminarized even at a heating level that the tube and annular flows completely cause laminarization.

8

American Institute of Aeronautics and Astronautics 


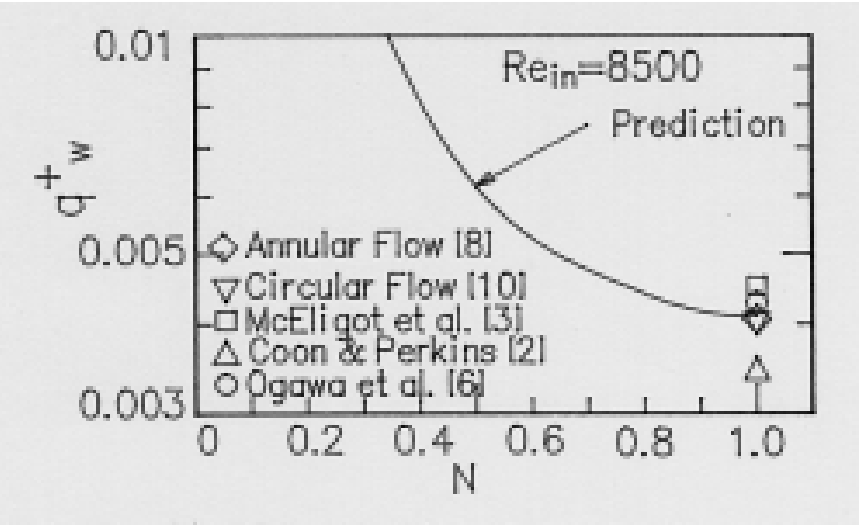

Figure 7 Laminarization map on $\mathrm{N}-\mathrm{q}^{+}$w plot

\section{SUMMARY}

$\mathrm{k}-\varepsilon-\mathrm{t}^{2}-\varepsilon \mathrm{t}$ model has been employed to numerically investigate fluid flow and heat transfer in a channel heated with uniform heat flux from both side-walls. Consideration is given to the effects of $\mathrm{N}$ on the occurrence of laminarization. The results are summarized as follows:

1. If the channel is simultaneously heated from both walls with high uniform heat flux, a substantial reduction of the local Stanton number causes laminarization along the flow. Therefore, the fluid flow in the channel is laminarized, just as in the tube flow case.

2. When laminarization takes place, the velocity and temperature gradients in the vicinity of the channel wall decrease along the flow, resulting in a substantial attenuation in both the turbulent kinetic energy and the temperature variance over the entire channel cross section. Consequently, the turbulent heat flux is diminished by a decrease in the turbulent kinetic energy and temperature variance over the channel cross section, resulting in the deterioration of heat-transfer performance.

3. If the channel is heated from only one side wall, substantial reduction of the local Stanton number is suppressed, resulting in no laminarization. This behavior is the same as that in an annulus heated with an only one wall. This is because the trend towards laminarization is always suppressed by the turbulent kinetic energy produced in the region near the insulated wall.
4. The occurrence of laminarization is affected by the heat flux ratio of both side-walls.

\section{REFERENCES}

1. C. A. Bankston, The Transition from Turbulent to Laminar Gas Flow in a Heated Pipe, Trans. ASME, Ser. C, vol. 92, no. 4, pp. 569-579, 1970.

2. C. W. Coon and H. C. Perkins, Transition from the Turbulent to the Laminar Regime for Internal Convective Flow with Large Property Variations, Trans. ASME, Ser. C, vol. 92, no. 3, pp. 506-512, 1970.

3. D. M. McEligot, C. M. Coon and H. C. Perkins, Relaminarization in Tubes, J. Heat \& Mass Transf., vol. 13, no. 2, pp. 431-433, 1970.

4. K. R. Perkins, K. W. Schade and D. M. McEligot, Heated Laminarizing Gas Flow in a Square Duct, $J$. Heat and Mass Transfer, vol. 16, no. 3, pp.897-916, 1973.

5. Y. Mori and K. Watanabe, Reduction in Heated Transfer Performance due to High Heat Flux, Trans. Jpn. Soc. Mech. Eng., (in Japanese), vol. 45, no. 397, B, pp. 1343-1353, 1979.

4. M. Ogawa, H. Kawamura, T. Takizuka and N. Akino, Experimental Study on Laminarization of Strongly Heated Gas Flow in Vertical Circular Tube, J. Atomic Energy Soc. Jpn., (in Japanese), vol. 24, no. 1, pp. 60-67, 1982.

7. S. Torii, A. Shimizu, S. Hasegawa and N. Kusama, Laminarization of Strongly Heated Annular Gas Flows, JSME Int. J., Ser. II, vol. 34, no. 2, pp. 157-168, 1991.

8. S. Fujii, N. Akino, M. Hishida, H Kawamura and K. Sanokawa, Numerical Studies on Laminarization of Heated Turbulent Gas Flow in Annular Duct, J. Atomic Energy Soc. Jpn., (in Japanese), vol. 33, no. 12, pp. 1180-1190, 1991.

9. S. Torii and W.-J. Yang, Laminarization of Turbulent Gas Flows inside a Strongly Heated Tube, Int. J. Heat Mass Transfer, vol. 40, no. 13, pp. 3105-3118, 1997.

10. S. Torii, A. Shimizu, S. Hasegawa and M. Higasa, Laminarization of Strongly Heated Gas Flows in a Circular Tube (Numerical Analysis by Means of a Modified k- $\varepsilon$ Model), JSME Int. J., Ser. II, vol. 33, no. 3, pp. 538-547, 1990.

11. H. Schlighting, Boundary-Layer Theory, 6th edition, McGraw-Hill, 1968. 
12. W. Rodi, Examples of Turbulence Models for Incompressible Flows, AIAA, J., vol. 20, pp. 872-879, 1982.

13. Y. Nagano and M. Hishida, Improved form of the k- $\varepsilon$ Model for Wall Turbulent Shear Flows, Trans. of ASME, Ser. D, vol. 109, pp. 156-160, 1987.

14. Y. Nagano and C. Kim, A Two-Equation Model for Heat Transport in Wall Turbulent Shear Flows, J. Heat Transfer, vol. 110, pp. 583-589, 1988.

15. S. V. Patankar, Numerical Heat Transfer and Fluid Flow, Hemisphere, Washington. D. C., 1980.

16. Propath Group, Propath: a program package for thermophysical property, version 4.1, 1987.

17. M. A. Nemira, J. A. Vilemas and V. M. Simonis, Heat Transfer to Turbulent Flow of Gases with Variable Physical Properties in Annuli (Correlation of Experimental Results), Heat Transfer - Soviet Research, vol. 12, pp. 104-112, 1980.

18. W. M. Kays and M. E. Crawford, Convective Heat and Mass Transfer, 2nd ed. MacGraw-Hill, New York, 1980. 
American Institute of Aeronautics and Astronautics 
American Institute of Aeronautics and Astronautics 